\title{
A loss of taurine and other amino acids from ventricles of patients undergoing bypass surgery
}

\author{
M-S Suleiman, H C Fernando, W C Dihmis, J A Hutter, R A Chapman
}

\begin{abstract}
Objective-To study the changes in amino acid content of left ventricles of patients during cardiac surgery that involves cardiopulmonary bypass and cold cardioplegia.
\end{abstract}

Design-Biopsy specimens (up to 10 mg wet weight) from the left ventricle of 30 patients undergoing coronary artery bypass graft and valve replacement surgery on cardiopulmonary bypass (protected by cold cardioplegia with St Thomas' solution) were taken immediately before the infusion of the cardioplegic solution and just before the removal of the cross clamp, and were analysed for their amino acid content.

Results-Of the most abundant cellular amino acids in the left ventricle taurine, glutamine, glutamate, and aspartate, but not alanine, showed a significant fall during the period of cross clamping. A rise in intracellular sodium (Na) is known to occur during cold cardioplegic arrest so that an activation of an amino acid/Na efflux, similar to that seen in animal experiments, seems a likely mechanism. The anomalous behaviour of alanine suggests some recovery of metabolism.

Conclusions-The loss of a amino acids (by contrast with the loss of taurine) will depress protein synthesis and reduce energy reserves after cardiac surgery. Attempts to preserve the concentrations of intracellular $\alpha$ amino acids must be balanced against the need to regulate intracellular $\mathrm{Na}$ concentration and hence intracellular $\mathrm{pH}$ and calcium ions. The presence of $a$ amino acids in the cardioplegic solution (or in a resuscitation solution) should maintain the intracellular concentrations and favour activation of the taurine/ $\mathrm{Na}$ symport to oppose the rise in intracellular $\mathrm{Na}$ concentration. Because the reservoir of tissue taurine is limited, the potential benefits of increasing the concentration of taurine in the heart by diet before surgery and addition of $a$ amino acids to the cardioplegic solution merits further assessment.

(Br Heart $\mathcal{f}$ 1993;69:241-245)

The concentration of amino acids in blood is raised in patients with acute myocardial infarction $^{12}$ and unstable angina, ${ }^{34}$ and after cardiac surgery. ${ }^{56} \mathrm{~A}$ fall in the amino acid content of the heart and an increase in amino acids in the blood is seen in animal studies after ligation of the coronary arteries and during hypoxia, and accompanies drug induced cardiac necrosis..$^{7-9}$ In the isolated guinea pig heart, a fall in intracellular concentrations of amino acids, in particular taurine, is provoked by a reduced gradient of sodium $(\mathrm{Na})$ ions across the cell membrane. This fall has been interpreted as an activation of a specific transport system because the appearance of taurine in the effluent is not associated with the appearance of cellular proteins or other metabolites and is blocked by specific inhibitors of taurine transport. Furthermore, when intracellular taurine is increased experimentally in isolated myocytes, a reduction of intracellular $\mathrm{Na}$ activity is seen at rest and during exposure to cardiac glycosides or media lacking divalent cations..$^{10}$ Intracellular $\mathrm{Na}$ rises when either the activity of the ouabain sensitive Na pump is reduced or the influx of $\mathrm{Na}+$ is increased-for example, during hypothermia, ${ }^{11}$ depletion of bathing concentrations of divalent cations, ${ }^{1213}$ hypokalaemia, ${ }^{13}$ ischaemia, ${ }^{14}$ hypoxia, ${ }^{15}$ and exposure to cardiac glycosides. ${ }^{11-13} \mathrm{~A}$ coupled efflux of taurine with $\mathrm{Na}$ would act to oppose the rise of intracellular $\mathrm{Na}$ under these conditions. The maintenance of a large inwardly directed $\mathrm{Na}$ gradient across the myocyte membrane is essential for the regulation of intracellular $\mathrm{pH}$ and free calcium ( $\mathrm{Ca}$ ) and hence normal cellular function. The fall in the concentration of $a$ amino acids in the heart may be due partly to metabolism (unlike taurine, which is very slowly metabolised) ${ }^{16}$ but a movement across the cell membrane is suggested by the relation to the rise in intracellular $\mathrm{Na} .{ }^{10}$ Cold cardioplegia (with a medium containing $\mathrm{Na}+$ ) is known to result in a rise in intracellular $\mathbf{N a}^{17}$ and might therefore be expected to provoke a loss of amino acids. This loss of amino acids would cause the fall in protein synthesis seen after calcium ( $\mathrm{Ca}$ ) depletion, ischaemia, or anoxia in animal hearts. ${ }^{18}$ We therefore set out to find the changes in taurine and amino acids in the ventricles of patients who were undergoing cardiac surgery on cardiopulmonary bypass with cardiac ischaemia protected by cold crystaloid cardioplegia.

Patients and methods

PATIENTS

All patients gave their informed consent for 
the study, which was approved by the local ethics committee. Thirty patients (24 men and six women) undergoing either coronary artery bypass graft $(n=21)$ or aortic or mitral valve replacement surgery $(n=9)$ were monitored for changes in taurine and free $a$ amino acid concentrations in biopsy specimens from their left ventricles. Cardiopulmonary bypass was initiated with drainage from the right atrium and return to the ascending aorta. The aorta was then cross clamped proximal to arterial return to produce cardiac ischaemia. A standard St Thomas' cardioplegic solution (composition in mmol.1-1 $: 16 \mathrm{MgCl}_{2} 6 \mathrm{H}_{2} \mathrm{O} ; 2 \mathrm{CaCl}_{2} ; 20 \mathrm{KCl}$; $147 \mathrm{NaCl} ; 1.0$ procaine $\mathrm{HCl}$ ) at $4^{\circ} \mathrm{C}$ was infused directly into the aortic root for the coronary bypass grafts or into the ostia of the coronary arteries for valve replacement. After this injection the temperature of the heart fell to around $8^{\circ} \mathrm{C}$ and rose slowly during the operation to around $15-20^{\circ} \mathrm{C}$. The minimum core temperature was monitored throughout and ranged between $26-29^{\circ} \mathrm{C}$. In all the patients 1 litre of cardioplegic solution was injected initially. In a few cases, depending on the appearance of electromechanical activity, an additional dose was subsequently injected. The ischaemic time during these operations ranged between 25 and 110 minutes.

Myocardial biopsy specimens (4-10 mg wet weight) were taken from the apex of the left ventricle with a "Tru-cut" needle. The first biopsy specimen was taken as soon as possible after starting cardiopulmonary bypass. After the period of ischaemia a second specimen was taken, and both specimens were stored in a freezer (at $-4^{\circ} \mathrm{C}$ ) until analysed.

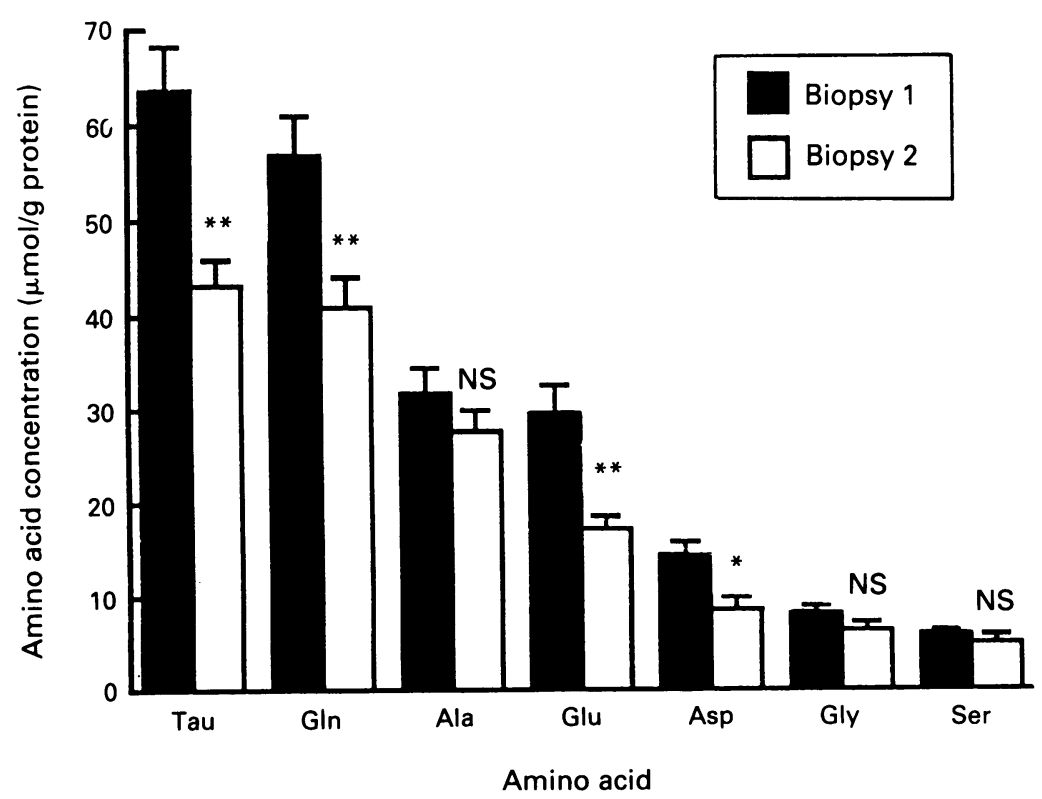

Figure 1 Changes in taurine and principle a amino acids in ventricular biopsy specimens taken from 30 patients undergoing cardiac bypass surgery. The first biopsy specimens were taken after starting cardiopulmonary bypass and the second after a period of ischaemia protected by cold cardioplegia. Values are mean (SEM). ${ }^{*} p<0.005 ;{ }^{\star *} p<0.001$. See table for abbreviations.
DETERMINATION OF TAURINE AND OTHER $a$ AMINO ACIDS IN VENTRICULAR BIOPSY SPECIMENS

Biopsy specimens were homogenised in 0.25 $\mathrm{ml}$ ice cold double distilled water and a $10 \mu \mathrm{l}$ aliquot was taken for protein determination and $0.2 \mathrm{ml}$ was added to Millipore ultrafiltration units and filtered by combined filtration centrifugation at $14000 \mathrm{rpm}$ and $20^{\circ} \mathrm{C}$, with an Eppendorf refrigerated centrifuge 5402. The filtrate was then vacuum dried and the phenylisothiocarbamyl derivitised amino acids $^{20}$ were separated by high performance liquid chromatography (HPLC) on a $15 \mathrm{~cm}$ $\times 4.6 \mathrm{~cm}$ Spherisorb $3 \mu \mathrm{m}$ ODS 2 column with two Waters 510 delivery systems. The solvents used were $0 \cdot 14 \mathrm{M} \mathrm{Na}$ acetate, 850 $\mu 1.1^{-1}$ triethylamine $\mathrm{pH} 5 \cdot 6(\mathrm{~A})$ and $60 \%$ acetonitrile (B) gradients were of $0 \% \mathrm{~B}$ for $1 \cdot 2$ minutes; $0-42 \%$ B for 10.8 minutes (convex curve); and $100 \% \mathrm{~B}$ for four minutes, at 0.8 ml.min. ${ }^{-1}$ This technique for amino acid determination has an inherent error of around 5\%.

Protein determination was carried out by the Lowry method with bovine serum albumin as a standard..$^{21}$ To avoid errors in measuring the protein content with this method, another reference for total protein was measured with a colorimetric microprotein determination kit from Sigma Diagnostics (cat no 610-A).

Data are expressed as mean (SEM) and $n$ refers to number of biopsy specimens. Statistical analysis was performed with two tailed $T$ test for paired data and a MannWhitney non parametric test available on a Stat View package for the Macintosh SE/30 computer. The power of statistics was also assessed for positive and negative differences between the means. ${ }^{22}$

\section{Results}

The concentrations of amino acids in biopsy specimens taken from the apex of the left ventricle of patients a few minutes after the start of cardiopulmonary bypass showed a much greater variability than that found in animal hearts. ${ }^{10}$ Biopsy specimens taken just before the cross clamp was removed after 25-110 minutes of cardiac ischaemia protected by cold cardioplegia with St Thomas' solution showed a significant fall in the amino acid content (fig 1). This fall was generally greatest for the amino acids occurring at the highest concentrations-namely, taurine, glutamine, glutamate, and aspartate $(\mathrm{p}<0.001$; paired $T$ test; $p<0.05$ Mann-Whitney). Alanine, however, at a concentration below taurine and glutamine but above aspartate and glutamate, showed a small fall that was not significant $(p>0.05$ paired $T$ test and Mann-Whitney). The amino acids that occur at concentrations below $10 \mu \mathrm{mol} . \mathrm{g}^{-1}$ protein showed little change. The loss of taurine, glutamine, glutamate, and aspartate was generally found to be largest in the patients who had the highest concentration in the first biopsy specimen. Figure 2 shows the change in 
Figure 2 Change in taurine $(A)$ and the $\alpha$ amino acid glutamate (B) in the ventricular biopsy specimens taken from 30 patients undergoing cardiac bypass surgery. The biopsy specimens were taken as described in fig 1 . The changes in the mean (SEM) for amino acids in both biopsy specimens are also shown.
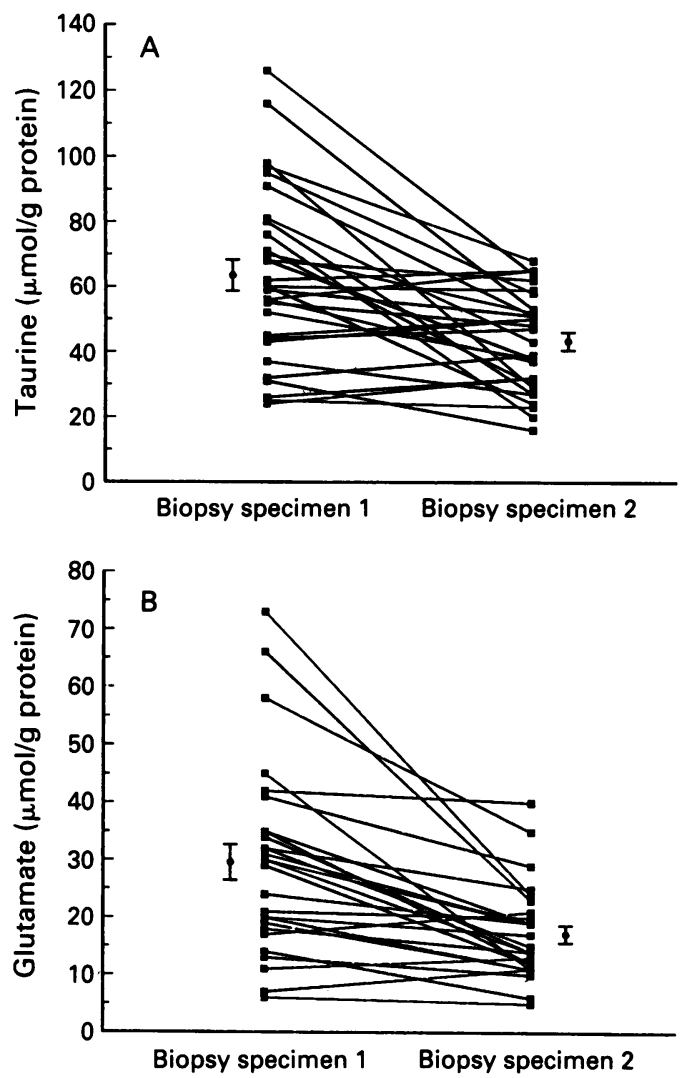

taurine and glutamate for individual patients. Calculations of the statistical power showed that the sample size was adequate for the data for alanine not to be significantly different at the $90 \%$ level.

The large variability in the concentrations of amino acids found in patients, the small numbers of patients, and the similar periods of ischaemia make conclusions based on further analysis of the data tentative. If the data for taurine, however, are grouped according to the periods of increasing ischaemia in steps of 10 minutes, a tentative time course for taurine loss can be found. Little or no fall in taurine occurred over the first 20-30 minutes followed by a steady decline over the next hour to a lower maintained plateau.

Although tissue amino acids concentrations are expressed as $\mu \mathrm{mol} . \mathrm{g}^{-1}$ protein, it is
Concentrations of amino acids in biopsy specimens taken before infusion for cardioplegia

\begin{tabular}{|c|c|c|c|}
\hline \multirow[b]{2}{*}{ Amino acid } & \multicolumn{2}{|l|}{ Tissue concentration } & \multirow{2}{*}{$\begin{array}{l}\% \text { of total amino } \\
\text { acid pool }\end{array}$} \\
\hline & ( $\mu$ mol.g $g^{-1}$ protein) & (mmol.kg' wet weight) & \\
\hline Taurine (tau) & $63 \cdot 4(4 \cdot 9)$ & $9 \cdot 5$ & $26 \cdot 8$ \\
\hline Glutamine (gln) & $56.9(4.0)$ & $8 \cdot 5$ & $24 \cdot 0$ \\
\hline Alanine (ala) & $31.9(2.6)$ & $4 \cdot 8$ & $13 \cdot 6$ \\
\hline Glutamate (glu) & $29 \cdot 6(3 \cdot 1)$ & $4 \cdot 4$ & $12 \cdot 4$ \\
\hline Aspartate (asp) & $14 \cdot 4(1 \cdot 7)$ & $2 \cdot 2$ & $6 \cdot 2$ \\
\hline Glycine (gly) & $8 \cdot 2(0 \cdot 8)$ & $1 \cdot 2$ & $3 \cdot 3$ \\
\hline Serine (ser) & $5.7(0.5)$ & 0.9 & $2 \cdot 5$ \\
\hline Threonine & $4.3(0.5)$ & $0 \cdot 6$ & $1 \cdot 7$ \\
\hline Leucine & $4.0(0.5)$ & $0 \cdot 6$ & $1 \cdot 7$ \\
\hline Valine & $4.0(0.4)$ & $0 \cdot 6$ & $1 \cdot 7$ \\
\hline Lysine & $3.2(0.4)$ & 0.5 & 1.4 \\
\hline Arginine & $2.4(0.4)$ & 0.4 & $1 \cdot 1$ \\
\hline Tyrosine & $2 \cdot 2(0 \cdot 2)$ & 0.3 & 0.8 \\
\hline Others & $6 \cdot 0$ & 0.9 & $2 \cdot 5$ \\
\hline
\end{tabular}

It is assumed that $0.15 \mathrm{~g}$ protein is present in $1.0 \mathrm{~g}$ wet weight of cardiac tissue. Values are means (SEM). possible to convert these values into mmol. $\mathrm{kg}^{-1}$ tissue wet weight assuming that each $\mathrm{g}$ wet weight of cardiac tissue contains $0.15 \mathrm{~g}$ protein. ${ }^{23}$ Table 1 shows the resting concentration (specimen 1) of the free amino acids as found by phenylisothiocarbamyl derivitisation. The total free amino acid pool in the ventricles of the these patients was around $35 \mathrm{mmol} . \mathrm{kg}^{-1}$ wet weight. These values show that, unlike other animal heart tissues, in which taurine can reach up to $50 \%$ of the total free amino acids, the intracellular concentration of taurine in the ventricle of patients contributes only $27 \%$ to the total free amino acid pool (similar to that of glutamine) in cardiac cells. The calculated concentration of glutamate in the first ventricular specimen (table 1) was similar to the concentration found previously for much larger biopsy specimens from the human left ventricles. ${ }^{24}$

\section{Discussion}

During cardiac surgery involving cold cardioplegia, a mean fall in free amino acids in the ventricular specimens of more than $50 \mu \mathrm{mol} . \mathrm{g}^{-1}$ protein $\left(>8 \mathrm{mmol} \cdot \mathrm{kg}^{-1}\right.$ wet weight) was seen. The fall in cellular taurine is consistent with that provoked in animal experiments by ischaemia ${ }^{4-9}$ and would be consistent with the heart as the source of taurine that appears in the blood after cardiac surgery, myocardial infarction, and unstable angina. ${ }^{1-3}$ The fall of tissue taurine was larger in patients with higher initial concentrations suggesting that the loss is affected by the size of the transmembrane gradient. In experiments on isolated guinea pig hearts an efflux of taurine has been shown to depend on the transmembrane $\mathrm{Na}$ gradient in ways consistent with the activity of a $\mathrm{Na}$ /taurine symport similar to that found in other tissues. Ischaemia, hypothermia, and cold cardioplegia result in raised intracellular $\mathrm{Na}$ concentration and so a similar mechanism is likely to be responsible for the loss of taurine during bypass surgery, especially as taurine is slowly metabolised and not incorporated into proteins. In our measurements, unlike the animal experiments, an accumulation of amino acids and water in the extracellular space is a likely additional complication of the ischaemia. This accumulation will act to limit efflux from the myocytes and may be in part responsible for the greater fall in amino acids that occurred at the higher initial intracellular concentrations.

Part of any change in the concentration of $a$ amino acids during cold cardioplegia may be due to effects on metabolism and protein synthesis. ${ }^{25}$ Despite this, the transport of an $a$ amino acid with $\mathrm{Na}+$ across the membrane may be expected to contribute because metabolic activity is reduced but transport processes persist in the cold. ${ }^{26}$ The much smaller change in tissue alanine, as compared with taurine, glutamine, glutamate, and aspartate suggests that some recovery of anaerobic metabolism occurs as the tempera- 
ture of the heart rises during surgery. The heart is known to respond to the accumulation of lactate by converting pyruvate into alanine by means of glutamate and aspartate $^{27} 28$ so that part of the fall in glutamate and aspartate and the maintained concentration of alanine might thereby result. This is consistent with the fall in glutamate being proportionately the largest (fig 1). The alanine: glutamate ratio has been used to assess changes in metabolism during studies of ischaemia in animal experiments. ${ }^{29}$ This ratio for the present data averaged over each 10 minute period of ischaemia, showed little or no increase for up to 40 minutes. After 40 min of ischaemia, however, there was a steady rise in the ratio that seemed to saturate beyond $70 \mathrm{~min}$. This suggests that it is over this time that the rise in temperature reactivates metabolism. Because of the small sample size and the averaging procedures used, this time course can only be tentative (there were only four patients with a period of ischaemia $>80 \mathrm{~min}$ ).

These results show that one of the stated aims of cardioplegia, namely to maintain the concentrations of intracellular $a$ amino acids ${ }^{19}$ is not achieved with St Thomas' solution for periods of ischaemia above 20 minutes. To maintain the intracellular concentrations of these amino acids, their inclusion in the cardioplegic solution at concentrations well above that in normal plasma ${ }^{24}$ should be carefully considered. This is because if the loss of amino acids is coupled to $\mathrm{Na}^{+}$, the preservation of tissue amino acid concentrations will also reduce the $\mathrm{Na}$ efflux and thereby result in a greater increase in intracellular concentrations of $\mathrm{Na}$. This means that the strategy will be self defeating because the amino acid efflux will simply be activated at the higher concentration of intracellular $\mathrm{Na}$. A potentially more dangerous consequence of the increased $\mathrm{Na}$ will also result from the effects on the $\mathrm{Na} / \mathrm{H}$ and $\mathrm{Na} / \mathrm{Ca}$ exchangers, which will compromise the regulation of intracellular $\mathrm{pH}$ and $\mathrm{Ca}^{2+}$ concentration, both of which are critical for normal cellular function. By contrast the loss of taurine together with $\mathrm{Na}^{+}$from the myocytes will reduce the rise in intracellular concentration of $\mathrm{Na}$ and should have little or no direct effect on metabolism or protein synthesis. This means that the inclusion of the $a$ amino acids in the cardioplegic solution, at values higher than in the plasma, could reduce their loss whereas the efflux of $\mathrm{Na}^{+}$together with taurine would be maintained. Another possibility would be to use a resuscitation medium rich in aspartate and glutamate as advocated by Buckberg. ${ }^{19}$ The fact that taurine is not of immediate metabolic importance to the heart and yet is lost together with $\mathrm{Na}^{+}$could be exploited further to maintain concentrations of $a$ amino acids, if intracellular taurine concentrations in the cardiac cells could be raised before surgery. It may be possible to achieve that through the diet because $4 \mathrm{~g}$ of taurine a day improved the cardiac function of patients with congestive heart failure. ${ }^{30}$

This work was supported by the British Heart Foundation We thank Dr W Mawby and Mr A Britton performing HPLC analysis for taurine and other amino acids and members of the Department of Cardiac Surgery, Bristol Royal Infirmary for their help during the collection of biopsy specimens.

1 Lombardini JB, Cooper MW. Elevated blood taurine levels in acute evolving myocardial infarction. $¥ \mathrm{Lab} \mathrm{Clin}$ Med $1981 ; 98: 849-59$
Mels in acute evolving

2 Chanin M, Roberts E, Goldman A. Influence of experimental myocardial infarction on free amino acids of dog heart. Circ Res 1956;4:713-17.

3 Bhatnagar SK, Welty JD, Al-Yusuf AR. Significance of blood taurine levels in patients with first time acute ischemic cardiac pain. Int $\mathcal{F}$ Cardiol 1990;27:361-6.

4 Mudge GH, Mills RM, Taegtmeyer H, Gorlin R, Lesch $M$. Alterations of myocardial amino acid metabolism in chronic ischemic heart disease. $₹$ Clin Invest 1976;58: chronic isch-92.

5 Cooper MW, Lombardini JB. Elevated blood taurine levels after myocardial infarction or cardiovascular surgery. Is there any significance? Adv Exp Med Biol 1981 139:191-205

6 Lombardini JB, Bricker DL. Effects of cardiovascular surgery on blood concentrations of taurine and amino acids. Proc Soc Exp Biol Med 1981;167:498-505.

7 Crass MF, Lombardini JB. Loss of cardiac muscle taurine after acute left ventricular ischemia. Life Science 1977; 21:951-8.

8 Crass MF, Lombardini JB. Release of tissue taurine from the oxygen deficient perfused rat heart. Proc Soc Exp the oxygen deficient perfuse

9 Lombardini JB. Effects of isoproterenol and methoxamine on the contents of taurine in rat tissue. $\mathcal{F}$ Pharmacol Exp Ther 1980;213:399-405.

10 Suleiman MS, Rodrigo GC, Chapman RA Interdependence of intracellular taurine and intracellular sodium in the guinea-pig heart. Cardiovasc Res 1992;26:897-905.

11 Suleiman MS, Chapman RA. The effect of temperature on the rise in intracellular sodium during calcium depletion in ferret ventricular muscle and the mechanism of the alleviation of the calcium paradox by hypothermia. the alleviation of the calcium

12 Bhojani IH, Chapman RA. The effects of bathing sodium ions upon the intracellular sodium activity in calciumfree media and the calcium paradox of isolated ferre ventricular muscle. $\mathcal{F}$ Mol Cell Cardiol 1990;22:507-22.

13 Chapman RA, Fozzard HA, Friedlander IR, January CT Effect of $\mathrm{Ca} / \mathrm{Mg}$ removal on $\mathrm{a}_{\mathrm{Na}^{i}}{ }^{{ }^{2}}{ }_{\mathrm{K}}{ }^{1}$ and tension in cardiac Purkinje fibers. Am $\mathcal{F}$ Physiol 1986;251:920-7.

14 Tani, M. Mechanisms of $\mathrm{Ca}^{2}+$ overload in reperfused ischemic myocardium. Ann Rev Physiol 1990;52: 543-59.

15 Diederiches F, Wittenberg H, Sommerfeld U. Myocardial cell damage and breakdown of cation homeostasis during conditions of ischemia and reperfusion, the oxygen ing conditions of ischemia and reperfusion, the oxygen paradox and reduced extracellula
Clin Biochem 1990;28:139-48.'

16 Huxtable RJ, Laird HE, Lippincott S. Rapid depletion of tissue taurine content by guanidinoethyl sulfonate. In Schaffer S, Baskin S, Kocsis J, eds. The effects of taurin on excitable tissues. New York: Spectrum Publications, 1981:231-245.

17 Kohno H, Shiki K, Ueno Y, Tokunaga K. Cold storage of the rat heart for transplantation. $f$ Thorac Cardiovasc Surg 1987;93:86-94.

18 Cheung JY, Thompson IG, Bonventre IV. Effect of extracellular calcium removal and anoxia on isolated rat cellular calcium removal and anoxia on

19 Buckberg GD. Strategies and logic of cardioplegic delivery to prevent, avoid and reverse ischemic and reperfusion damage. F Thorac Cardiovasc Surg 1987;93:127-39.

20 Cohen SA, Bidlingmeyer BA, Tarvin TL. PITC derivatives in amino acid analysis. Nature 1986;320:769-70.

21 Lowry OH, Rosebrough NJ, Farr AL, Randall RJ. Protein measurement with the Folin phenol reagent. $\mathcal{f}$ Biol Chem 1951;193:265-75.

22 Kirkwood BR. Essentials of medical statistics. Oxford: Blackwell Sci Publications, 1988.

23 Van der Vusse GJ, Bilsen M, Willemsen P, Reneman $R$ The myocardial content of fatty acids and phospholipids during the calcium paradox. $\mathcal{F} \mathrm{Mol}$ Cell Cardiol 1988; 20:617-23.

24 Pisarenko OI, Portnyo VF, Studneva IM, Arapov AD, Korostylev AN. Glutamate-blood cardioplegia improves Korostylev AN. Glutamate-blood cardioplegia improves
ATP preservation in human myocardium. Biomed ATP preservation in human

25 Christensen HN, Kilberg MS. Amino acid transport across the plasma membrane: role of regulation in interorgan flows. In: Yudilevich DL, Boyd CAR, eds.
Amino acid transport in animal cells. Manchester: Amino acid transport in animal cells.
Manchester University Press, 1987:10-45. 
26 Poole RC, Halestrap AP, Price S, Levi A. The kinetics of transport of lactate and pyruvate into isolated cardiac transport of lactate and pyruvate into isolated cardiac

27 Peuhkurinen KJ, Takala TES, Nuutinen EM, Hassinen

IE. Tricarboxylic acid cycle metabolites during ischemia in isolated perfused rat heart. Am F Physiol 1983; 244:281-8

28 Pisarenko OI, Baranov AV, Pomerantsev EV, Studneva IM, Pavlov NA. Myocardial metabolism of glutamate and left ventricular function in patients with coronary arterial disease. Int $\mathcal{f}$ Cardiol 1989;23:43-52.

29 Conger KA, Garcia JH, Lossinsky AS, Kauffman FC. Effect of aldehyde fixation on selected substrates for energy metabolism and amino acids in mouse brain. $f$ Histochem Cytochem 1978;26:423-33.

30 Azuma J, Sawamura A, Awata N. Usefulness of taurine in chronic congestive heart failure and its prospective application. fap Circ f 1 1992;56:95-9. 